\title{
Pin-on-disc study of dry sliding behavior of Co-free HVOF- coated disc tested against different friction materials
}

\author{
Matteo FEDERICI ${ }^{1}$, Cinzia MENAPACE ${ }^{1}$, Alessandro MANCINI $^{2}$, Giovanni STRAFFELINI $^{1}$, Stefano \\ GIALANELLA ${ }^{1}$ \\ ${ }^{1}$ Department of Industrial Engineering, University of Trento, Trento 32122, Italy \\ ${ }^{2}$ Brembo S.p.A., Stezzano, Bergamo 24040, Italy \\ Received: 08 November 2019 / Revised: 31 January 2020 / Accepted: 14 October 2020 \\ (C) The author(s) 2020 .
}

\begin{abstract}
The dry sliding behavior of three commercial friction materials (codenamed FM1, FM2, and FM3) tested against a Co-free cermet coating produced by high-velocity oxy-fuel (HVOF) on gray cast-iron discs is investigated. FM1 is a conventional low-metallic friction material, FM2 is developed for using against HVOF-coated discs, and FM3 is a $\mathrm{Cu}$-free friction material with a low content of abrasives and a relatively high concentration of steel fibers. For the tribological evaluation, they are tested on a pin-on-disc (PoD) test rig against Co-free HVOF-coated discs, with particular attention to the running-in stage, which is fundamental for the establishment of a friction layer between the two mating surfaces, i.e., the pin and disc. The PoD tests are performed at room temperature (RT) and a high temperature (HT) of $300{ }^{\circ} \mathrm{C}$. At RT, all materials exhibit a long running-in stage. At HT, no running-in is observed in FM1 and FM2, whereas a shorter running-in period, with respect to the RT case, is observed in FM3 followed by the attainment of a comparatively high coefficient of friction. At RT, the pin wear is mild in all cases but severe at HT. FM3 shows the lowest wear rate at both temperatures. Moreover, the coated disc shows no wear when sliding against the FM3 friction material. All the results are interpreted considering the microstructural characteristics of the friction layers formed on the sliding surfaces. The findings of the present study provide insights into reducing wear in braking system components and hence reducing environmental particulate matter emissions from their wear, through the use of disc coatings.
\end{abstract}

Keywords: friction materials; sliding wear; high-velocity oxy-fuel (HVOF) coatings; pin-on-disc (PoD) testing

\section{Introduction}

High-velocity oxy-fuel (HVOF) cermet coatings are widely employed in tribological applications featuring sliding conditions such as sliding bearings, valves, and forging dies [1-3]. WC-Co and $\mathrm{Cr}_{3} \mathrm{C}_{2}-\mathrm{NiCr}$ cermet coatings are used against different counterface materials, such as steels or ceramics [4-7]. The reported specific wear coefficients can be extremely low, i.e., below $5 \times$ $10^{-15} \mathrm{~m}^{2} / \mathrm{N}$, depending on the coating quality and the main damage mechanisms [5, 8-10]. A comprehensive review of the damage mechanisms of HVOF WC$(\mathrm{W}, \mathrm{Cr})_{2} \mathrm{C}-\mathrm{Ni}$ and $\mathrm{WC}-\mathrm{CoCr}$ coatings dry sliding against a ceramic counterface was recently provided by Bolelli et al. $[9,11]$. At room temperature (RT), the wear mechanisms were discovered to be the abrasion of the metallic matrix, which involved the extraction of carbides from the coating surface, and the brittle cracking of both the metallic matrix and carbides. Furthermore, the tribo-oxidation of

* Corresponding author: Giovanni STRAFFELINI, E-mail: giovanni.straffelini@unitn.it 
the carbide phase occurred when the sliding velocities were sufficiently high. Furthermore, the authors identified a threshold temperature between 600 and $750{ }^{\circ} \mathrm{C}$ for the oxidation of the carbide phase and the metallic matrix. Such phenomena were discovered to be detrimental to the sliding wear resistance of the cermet coatings; therefore, $\mathrm{Cr}_{3} \mathrm{C}_{2}-\mathrm{NiCr}$ coatings are preferred in high-temperature (HT) applications [8].

Cermet coatings obtained via the HVOF technique are promising for brake systems comprising friction material pads sliding against a rotating disc [12-14]. In fact, disc wear contributes significantly to the overall system wear and hence to the release of wear particles into the environment [15]. Because the emission of wear particles is strictly associated with the wear of components in sliding contact [15], in principle, upon increasing the wear resistance of the counterface discs, a reduction in the emissions is expected. In a previous investigation [12], the dry sliding behavior of a commercial friction material against WC-CoCrand $\mathrm{Cr}_{3} \mathrm{C}_{2}-\mathrm{NiCr}$-coated discs was investigated at $\mathrm{RT}$ and $300{ }^{\circ} \mathrm{C}$. The steady-state friction coefficient detected during the RT pin-on-disc (PoD) tests was high, i.e., approximately 0.7 and 0.6 for the WC-CoCrand $\mathrm{Cr}_{3} \mathrm{C}_{2}-\mathrm{NiCr}$-coated discs, respectively. Moreover, a slight decrease was observed with increasing test temperature, and the specific wear coefficients of the coated discs were negligible in both cases. Federici et al. [16] investigated the effect of the initial surface roughness and skewness of cermet-coated discs and discovered that the best compromise between the frictional and wear performances and the industrial feasibility of a surface polishing process began at an average surface roughness of 1.0-1.5 $\mu \mathrm{m}$. Furthermore, the tribological characterization was extended to the running-in behavior [17] as a function of the initial surface finish of the coating. It was discovered that the best frictional and wear performances were achieved using polished discs only. The study of Wahlström et al. [18] demonstrated that significant potential of HVOF cermet coatings in reducing the emission of airborne particles associated with the material wear of braking systems. Similarly, Menapace et al. [19] extended the study to investigate the chemical and phase compositions of the airborne fractions of wear debris collected during dyno-bench tests using WC-CoCr-coated discs. One of the main results of the investigation was the detection of critical elements transferred from the coating to the airborne fraction of the wear debris, i.e., cobalt; this has raised additional concern. Because some chemical compounds of this element are considered hazardous to the human body [20], they must be removed from the coatings used in braking system applications. The issue of cobalt replacement in industrial machinery is in fact well known; several investigations [21-24] have been performed to obtain a valuable metallic matrix for cobalt replacement, and different solutions have been proposed. Zhang et al. [21] analyzed the wear behavior of an $\mathrm{Fe}_{48} \mathrm{Mo}_{14} \mathrm{Cr}_{15} \mathrm{Y}_{2} \mathrm{C}_{15} \mathrm{~B}_{6}$ amorphous coating and obtained promising results regarding their dry sliding friction and wear behaviors. Bolelli et al. [24] investigated the possibility of reinforcing Fe-based coatings with WC particles. The results of this preliminary investigation showed that the dry sliding wear rates of the newly developed Fe-based coatings were comparable to those of traditional WC-CoCr coatings, i.e., lower than $10^{-17} \mathrm{~m}^{2} / \mathrm{N}$. The same authors extended their investigations by testing different types of Fe-based coatings [25, 26]; they discovered that the detection of specific wear coefficients was still relatively low, i.e., on the magnitude order of $10^{-15} \mathrm{~m}^{2} / \mathrm{N}$.

To the best of our knowledge, the possibility of using Co-free HVOF coating on the surface of brake discs has not been investigated hitherto. The present investigation aims to partially fill this gap by evaluating the frictional and wear properties of a newly developed WC-FeCrAlY coating tested against three different friction materials. This coating might be able to overcome the release problem in the outer environment of cobalt-containing airborne wear debris generated during the use of coated brake discs. The present research focuses on the use of a PoD tribometer for evaluating the frictional and wear performances of the newly developed Co-free coating. The abovementioned investigations involving wear-resistant coatings revealed an important issue regarding the formation of an effective tribological layer. In fact, once the fraction of wear debris from the disc is reduced significantly, the buildup of secondary plateaus resulting from the compaction of the wear debris 
against the harder and tougher components of the friction material (primary plateaus) may become relatively difficult, thereby complicating the investigation of the peculiar running-in behavior. The running-in stage has been specifically investigated owing to its fundamental role in the tribological coupling between mating surfaces. Information from PoD characterization is widely used [17, 27-29] during the early development of new materials for braking systems to rank the material performances. Nevertheless, for the final assessment of the materials in ready-to-use conditions, dyno-bench and car tests are required.

\section{Materials}

A Co-free WC-FeCrAlY coating was deposited using the HVOF thermal spray technique onto traditional pearlitic gray cast iron discs with a hardness of $235 \pm$ 5 HV10. The nominal composition of the powder used for the thermal spray deposition, including the carbide phase and metallic matrix, is listed in Table 1 . The carbide and powder particle size ranges are shown as well.

The coating was deposited under standard conditions with a spraying distance of $380 \mathrm{~mm}$ between the torch and substrate disc. A mixed flux of kerosene $(25 \mathrm{~L} / \mathrm{h})$ and oxygen flux $(1,000 \mathrm{~L} / \mathrm{min})$ was used. The barrel length was approximately $100 \mathrm{~mm}$, the traverse torch speed was $550 \mathrm{~mm} / \mathrm{s}$, the powder feed rate was $70 \mathrm{~g} / \mathrm{min}$, and the carrier gas flow rate $\left(\mathrm{N}_{2}\right)$ was $7 \mathrm{~L} / \mathrm{min}$. The powder was deposited using a Diamond Jet 2600 HVOF torch onto a pearlitic gray cast iron substrate, which was prepared based on an industrial degreasing protocol, roughened via a traditional sandblasting process, and pre-heated to $150{ }^{\circ} \mathrm{C}$.

Table 1 Nominal chemical composition of starting powder of WC-FeCrAlY coating and carbide particle size.

\begin{tabular}{ccccc}
\hline Powder & $\begin{array}{c}\text { Carbide } \\
\text { phase }\end{array}$ & $\begin{array}{c}\text { Carbide } \\
\text { particle } \\
\text { size }(\mu \mathrm{m})\end{array}$ & $\begin{array}{c}\text { Powder } \\
\text { particle } \\
\text { size }(\mu \mathrm{m})\end{array}$ & $\begin{array}{c}\text { Metallic } \\
\text { matrix- } \\
\text { nominal } \\
\text { composition }\end{array}$ \\
\hline $\begin{array}{c}\text { WC- } \\
\text { FeCrAlY }\end{array}$ & & & & $12 \mathrm{wt} \% \mathrm{Fe}$ \\
& & $1-5$ & $15-45$ & $\begin{array}{c}3.5 \mathrm{wt} \% \mathrm{Cr} \\
1 \mathrm{wt} \% \mathrm{Al} \\
0.5 \mathrm{wt} \% \mathrm{Y}\end{array}$ \\
\hline
\end{tabular}

Based on the two former cited studies regarding the effect of roughness on the frictional and wear behaviors of HVOF-coated discs tested against friction materials [4, 5], the as-sprayed average roughness $\left(R_{\mathrm{a}}\right)$ and roughness skewness $\left(R_{\mathrm{sk}}\right)$ of the coated discs were reduced via an optimized industrial polishing procedure. The surface of the discs was analyzed using a Hommel Tester T1000 stylus profilometer. The scanning parameters were as follows: a sampling length of $15 \mathrm{~mm}$ and a scanning speed of $0.15 \mathrm{~mm} / \mathrm{s} ; R_{\mathrm{a}}$ was $1.4 \pm 0.2 \mu \mathrm{m}$, whereas $R_{\mathrm{sk}}$ was $(-1.5) \pm 0.3$. The coating thickness after polishing was approximately $70 \mu \mathrm{m}$.

The microstructural features of the coatings and friction materials were characterized via scanning electron microscopy (SEM, JEOL IT-300) equipped with an energy-dispersive X-ray spectroscopy (EDXS) probe for chemical analysis. The SEM micrograph of the coating cross-section is shown in Fig. 1(a). The coating is characterized by a low residual porosity and no cracks, i.e., two types of defects often observed in such coating type. Furthermore, the machining mark of the cast iron substrate, owing to a turning operation performed to create the specimens and
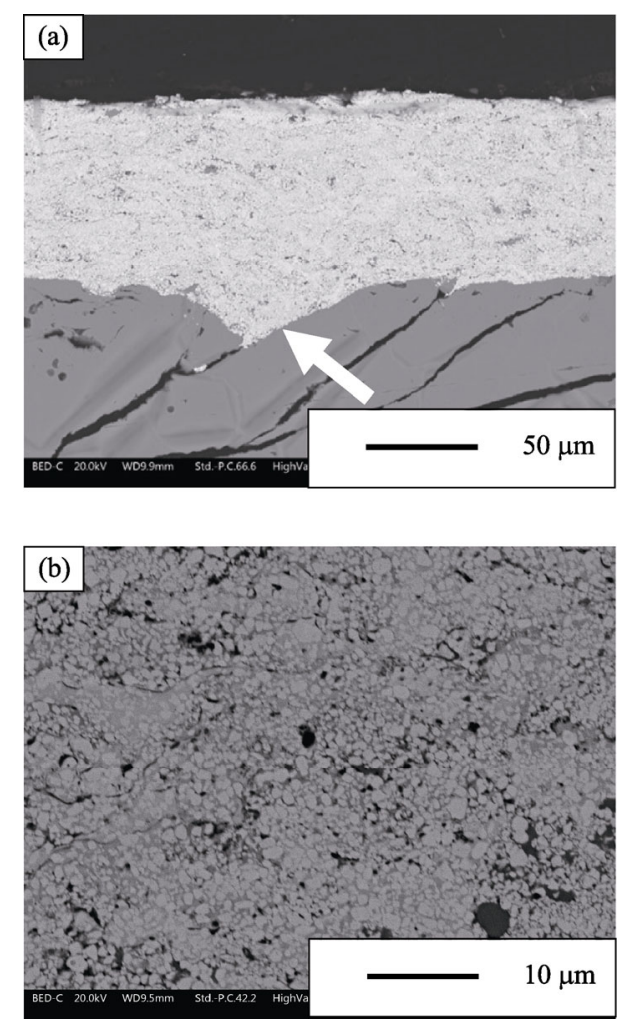

Fig. 1 SEM micrographs of coating cross-section after polishing. 
indicated with an arrow in the central region of the image, served as macroscopic mechanical interlocking between the coating and substrate, based on an established physical adhesion mechanism investigated in several studies [30-32]. In Fig. 1(b), the microstructure details of the coating are shown, where blocky carbide grains with almost rounded edges can be observed in the metal binder matrix.

Microhardness tests were conducted on the polished cross-section using a Future-Tech microhardness tester (model FM-310). A Vickers diamond indenter under a $300 \mathrm{~g}$ load and $10 \mathrm{~s}$ dwell time was used. The microhardness of the coating was 1,130 \pm 89 HV0.3. The sprayed coating was subjected to X-ray diffraction (XRD) analysis to verify the presence of parasitic phases typical in WC-containing coatings [33-35]. The analyses were performed using a Co $\mathrm{K} \alpha$ incident beam from an Italstructures IPD3000 diffractometer with an Inel CPS120 detector that simultaneously collected the signal over a $2 \theta$ angular range of $5^{\circ}-120^{\circ}$. The resulting XRD spectrum is shown in Fig. 2.

The results show a nanocrystalline metallic matrix and WC carbides. The nanocrystals are due to both the high deformation of the matrix that occurred during the collision of the particles with the substrate and to their particularly high cooling rate. Although the presence of additional minority phases could not be clearly assessed, the two broad diffraction peaks positioned at approximately $46.3^{\circ}$ and $48.2^{\circ}$

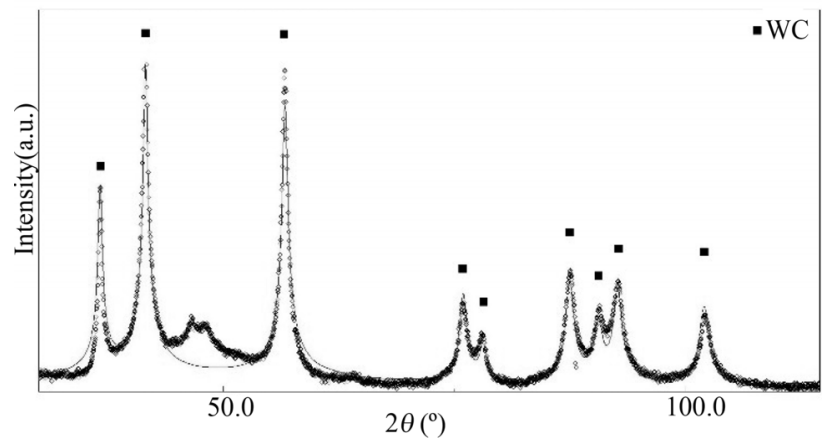

Fig. 2 XRD spectrum of WC-FeCrAlY coatings.

can be reasonably ascribed to the nanocrystalline $\mathrm{W}_{2} \mathrm{C}$ phase, with a corresponding estimated volume fraction below $5 \%$.

The friction materials used for the tribological characterization of the coated discs were three low-metallic brake pads. The first friction material, codenamed FM1, was the reference, and its composition is typical of commercial low-metallic lining materials. The other two, codenamed FM2 and FM3, were specifically developed for use against HVOF-coated discs. Furthermore, the third friction material (FM3) had a copper-free formulation. Their phase compositions were determined via XRD analysis. The XRD measurements were performed using a Rigaku SmartLab high-resolution diffractometer equipped with a $\mathrm{Cu} \mathrm{K} \alpha$ radiation source. Subsequently, a quantitative analysis was performed with Rietveld refinement [36], and the results obtained are listed in Table 2.

Table 2 Phase composition of friction materials used for tribological characterization of WC-FeCrAlY-coated discs. Hardness values are only indicative and were obtained from different literature.

\begin{tabular}{|c|c|c|c|c|c|}
\hline Role of constituents & Phases & Mohs hardness & $\begin{array}{c}\text { Concentration } \\
\text { of phases in } \\
\text { FM1 }(w t \%)\end{array}$ & $\begin{array}{c}\text { Concentration } \\
\text { of phases in } \\
\text { FM2 }(w t \%)\end{array}$ & $\begin{array}{c}\text { Concentration } \\
\text { of phases in } \\
\text { FM3 }(\mathrm{wt} \%)\end{array}$ \\
\hline \multirow{4}{*}{ Reinforcements } & Iron $(\mathrm{Fe}-\alpha)$ & $4-4.5$ & $4.8 \pm 0.4$ & $2.1 \pm 0.5$ & $27.5 \pm 0.8$ \\
\hline & Copper $(\mathrm{Cu})$ & 3 & $8.1 \pm 0.3$ & $3.9 \pm 0.2$ & - \\
\hline & $\operatorname{Brass}(\mathrm{Cu}+\mathrm{Zn})$ & 3.5 & $7.7 \pm 0.2$ & $4.3 \pm 0.3$ & - \\
\hline & Zinc $(\mathrm{Zn})$ & $2.5-3$ & $7.0 \pm 0.5$ & $2.1 \pm 0.6$ & - \\
\hline \multirow{5}{*}{ Abrasives } & Corundum $\left(\mathrm{Al}_{2} \mathrm{O}_{3}\right)$ & 9 & $17.8 \pm 0.5$ & $14.9 \pm 0.3$ & $5.5 \pm 0.4$ \\
\hline & Anatase $\left(\mathrm{TiO}_{2}\right)$ & $5.5-6$ & - & $6.0 \pm 0.7$ & - \\
\hline & Rutile $\left(\mathrm{TiO}_{2}\right)$ & 6 & - & $2.6 \pm 0.8$ & - \\
\hline & Chromite $\left(\mathrm{Fe}^{2+} \mathrm{Cr}_{2} \mathrm{O}_{4}\right)$ & 8 & $2.6 \pm 0.7$ & $1.8 \pm 0.9$ & $1.8 \pm 0.4$ \\
\hline & Periclase $(\mathrm{MgO})$ & 6 & $2.0 \pm 0.4$ & $2.6 \pm 0.5$ & $2.6 \pm 0.6$ \\
\hline \multirow{2}{*}{ Solid lubricant } & Graphite (C) & 1.5 & $25.6 \pm 0.2$ & $28.4 \pm 0.3$ & $26.4 \pm 0.5$ \\
\hline & Tin sulfide $(\mathrm{SnS})$ & $1-2$ & $1.2 \pm 0.5$ & $1.3 \pm 0.4$ & $1.4 \pm 0.4$ \\
\hline \multirow{3}{*}{ Fillers } & Kaolinite $\left(\mathrm{Al}_{2} \mathrm{Si}_{2} \mathrm{O}_{5}(\mathrm{OH})_{4}\right)$ & $2-2.5$ & $5.7 \pm 0.7$ & $7.1 \pm 0.6$ & - \\
\hline & Biotite $\left(\mathrm{K}\left(\mathrm{Mg}, \mathrm{Fe}^{2+}\right)_{3}\right)$ & $2.5-3$ & $17.5 \pm 0.4$ & $22.9 \pm 0.5$ & $25.7 \pm 0.6$ \\
\hline & Barite $\left(\mathrm{BaSO}_{4}\right)$ & $3-3.5$ & - & - & $9.1 \pm 0.5$ \\
\hline
\end{tabular}


Figure 3(a) shows an SEM micrograph of FM1. As shown, iron (i.e., steel) and brass are present in the form of chips or elongated reinforcing fibers, whereas copper is in the form of particles. Brass and copper increase the thermal conductivity of the material, thereby reducing the local thermal spots $[37,38]$. Tin was added in the form of sulfide as a solid lubricant. Carbon was present as graphite. The constituents containing silicon, aluminum, and magnesium were identified as biotite and kaolinite with the role of fillers. The EDXS maps in Figs. 3(b) and 3(c) show that they were present in the form of elongated layered structures and coherent with the relevant phyllosilicate structure of the two phases.
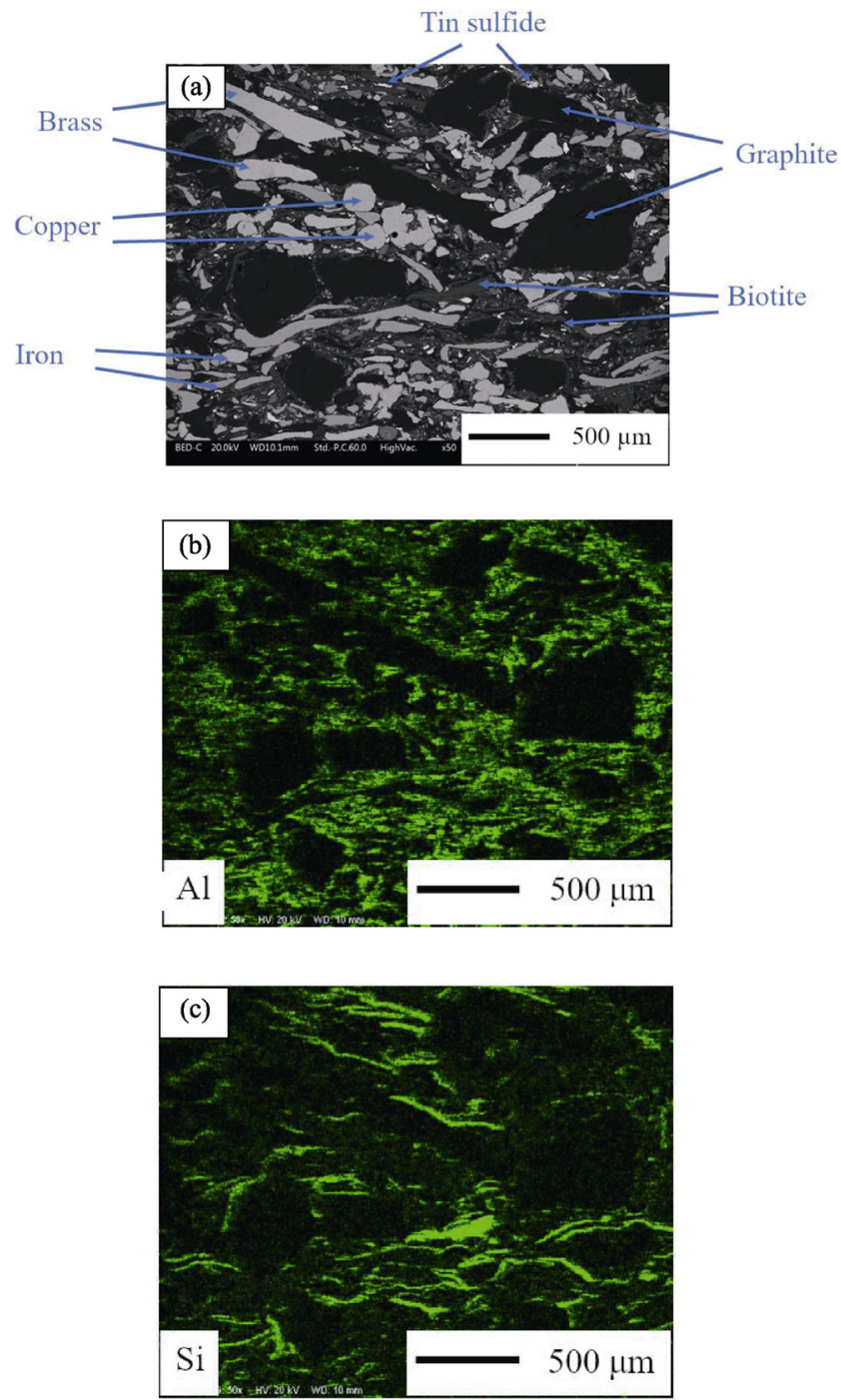

Fig. 3 SEM micrographs of FM1 with (a) identification of some constituents and EDXS elemental maps of (b) Al and (c) Si.
Furthermore, aluminum and magnesium were discovered in the form of rounded oxide particles serving as strong abrasives. Chromium was added as chromite, a mild abrasive.

Figure 4(a) shows an SEM micrograph of friction material 2 (FM2), and it is similar to that of FM1. Iron was mainly added as steel chips, whereas copper was present in the form of almost spherical particles. The longer fibers were made of brass. Moreover, titanium oxide was added as a strong abrasive, appearing as particularly small and well-dispersed particles, as revealed by the EDXS map shown in Fig. 4(b). Figure 5(a) shows an SEM micrograph of friction material 3 (FM3). It differed significantly from those of FM1 and FM2. Its abrasive amount decreased and copper was completely removed. Furthermore, its iron amount was higher compared to those in FM1 and FM2; it is noteworthy that iron is the only metallic ingredient in FM3. The presence of barium can be associated with barite, which is a widely used constituent of copper-free friction materials [39-41]. The roles of the different constituents on the tribological behavior of the different pin-disc couplings are illustrated in the following.
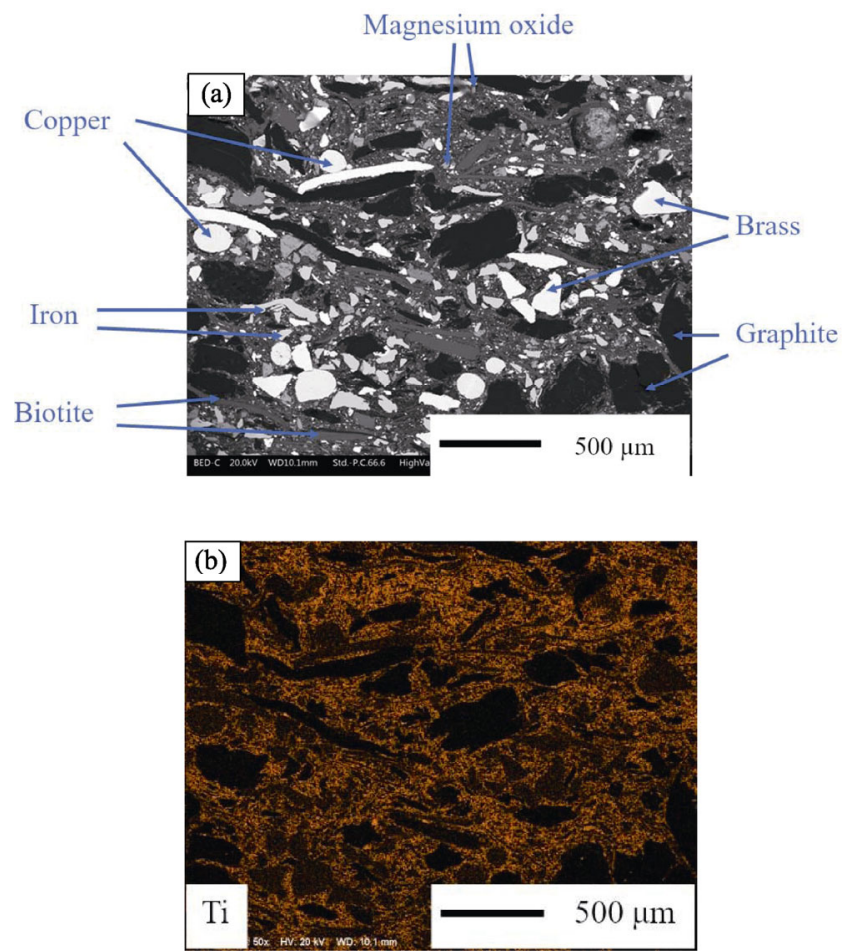

Fig. 4 SEM micrographs of FM2 with (a) identification of some constituents and (b) EDXS elemental map of Ti. 

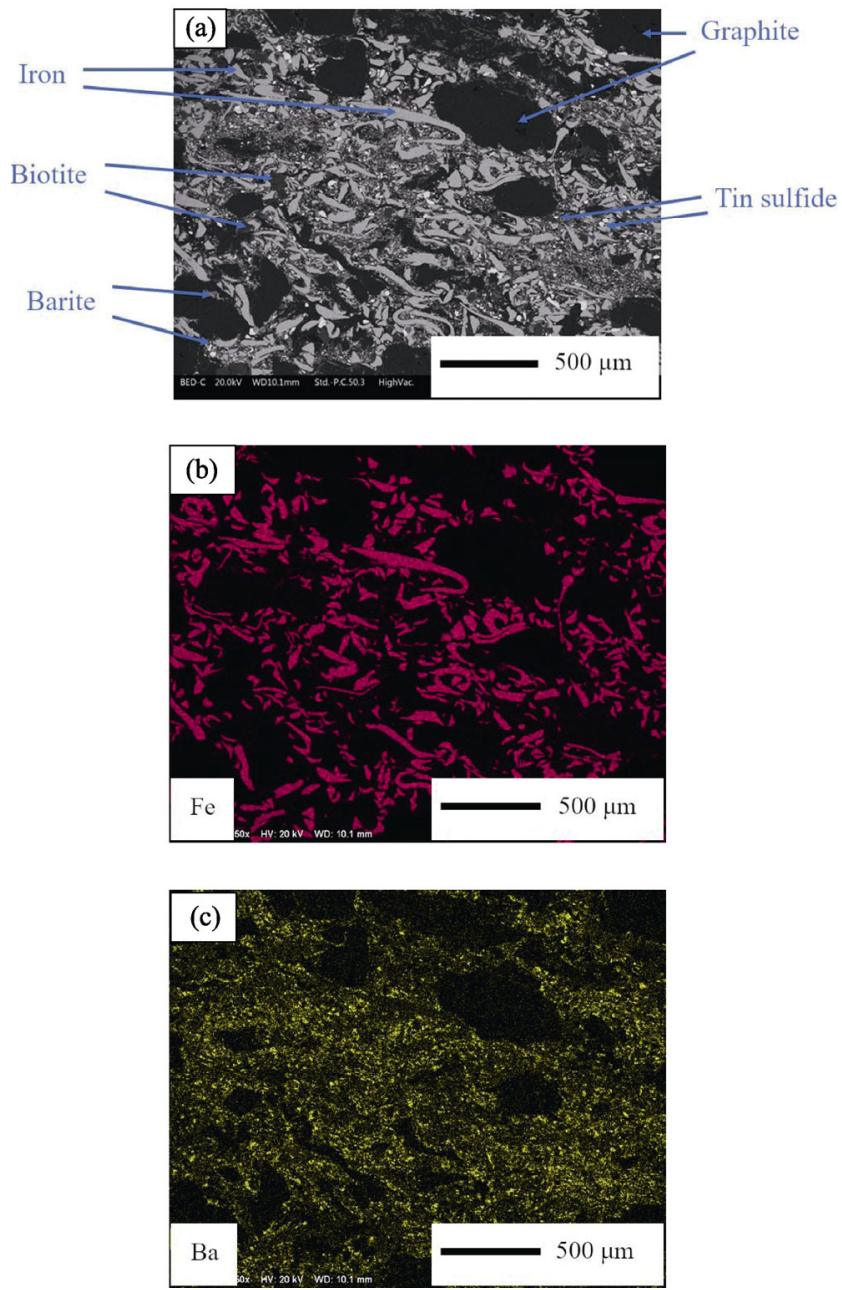

Fig. 5 SEM micrographs of friction material FM3 with (a) identification of some constituents and EDXS elemental map of (b) Fe and (c) Ba.

\section{PoD dry sliding tests}

The PoD tests were performed under dry sliding conditions using a Ducom Macro testing rig. The pins were mechanically machined from brake pads. They measured $10.0 \pm 0.1 \mathrm{~mm}$ in diameter and $12 \pm 1 \mathrm{~mm}$ in height. The coated discs used for the tribological characterization had a diameter of $63.0 \pm 0.1 \mathrm{~mm}$ and a thickness of $6.0 \pm 0.1 \mathrm{~mm}$. The tests were performed at RT and $300{ }^{\circ} \mathrm{C}$. During HT tests, the discs were heated using an induction coil that maintained the temperature through a closed-loop feedback control system. Based on previous inves- tigations [16, 17], the specimens were tested at a nominal contact pressure of $1 \mathrm{MPa}$ and a sliding speed of $1.57 \mathrm{~m} / \mathrm{s}$ for $50 \mathrm{~min}$. The temperature was controlled using a pyrometer and maintained using closed-loop feedback. Before each test, a bedding stage under the same sliding conditions was applied for $10 \mathrm{~min}$ to ensure conformal contact between the pin and the disc surface. The PoD tests were not aimed at simulating real braking conditions, but only at replicating the damage mechanisms at the disc/pad interface. Hence, the sliding conditions of the PoD tests were set similar to the disc/pad contact conditions during an urban braking action [10-12].

The pin wear rates were evaluated by measuring their mass losses before and after the tests using an analytical balance with a precision of $10^{-4} \mathrm{~g}$. The wear volumes were obtained by dividing the mass losses by the apparent density of the tested pins. In the present study, the wear data of the friction materials were expressed in the form of the specific wear coefficient $\left(K_{a}^{\text {Pin }}\right)$, calculated from the following relationship:

$$
K_{a}^{\text {Pin }}=\frac{V_{\text {Pin }}}{F_{\mathrm{N}} s}
$$

where $V_{\text {Pin }}$ is the calculated wear volume, $F_{\mathrm{N}}$ is the nominal contact force, and $s$ is the sliding distance. The results presented herein are the average of at least three repetitions. The wear of the discs was estimated via a profilometric analysis of the wear tracks. Five measurements were acquired in the radial direction across the wear track of each disc. The acquired profile was analyzed, and the wear track cross-section was calculated $\left(A_{\mathrm{wt}}\right)$. The average value of the area was used to calculate the wear volume of the discs, as follows:

$$
V_{\text {Disc }}=A_{\mathrm{wt}} 2 \pi R
$$

where $R$ is the average sliding radius. The specific wear rate of the discs ( $\left.K_{a}^{\text {Disc }}\right)$ was calculated as

$$
K_{a}^{\text {Disc }}=\frac{V_{\text {Disc }}}{F_{\mathrm{N}} s}
$$

\section{Experimental results}

\subsection{RT PoD tests}

The evolution of the friction coefficient is shown in Figs. 6(a)-6(c) for the three materials investigated. 
All the materials showed a continuous increase in the friction coefficient from an initial value of approximately 0.25 . The values of the friction coefficient attained at the end of the tests are listed in Table 3. It was clear that FM1 and FM2 showed similar friction coefficients, which were relatively higher than that of FM3.

The recorded disc wear profiles are shown in Fig. 7. In Table 3, the calculated pin and disc $K_{\mathrm{a}}$-values are listed. As for the friction coefficients, FM1 and FM2 showed similar behaviors, whereas FM3 showed less pin and disc wear. In fact, using the FM3 material, the disc wear was below the detectability limit of
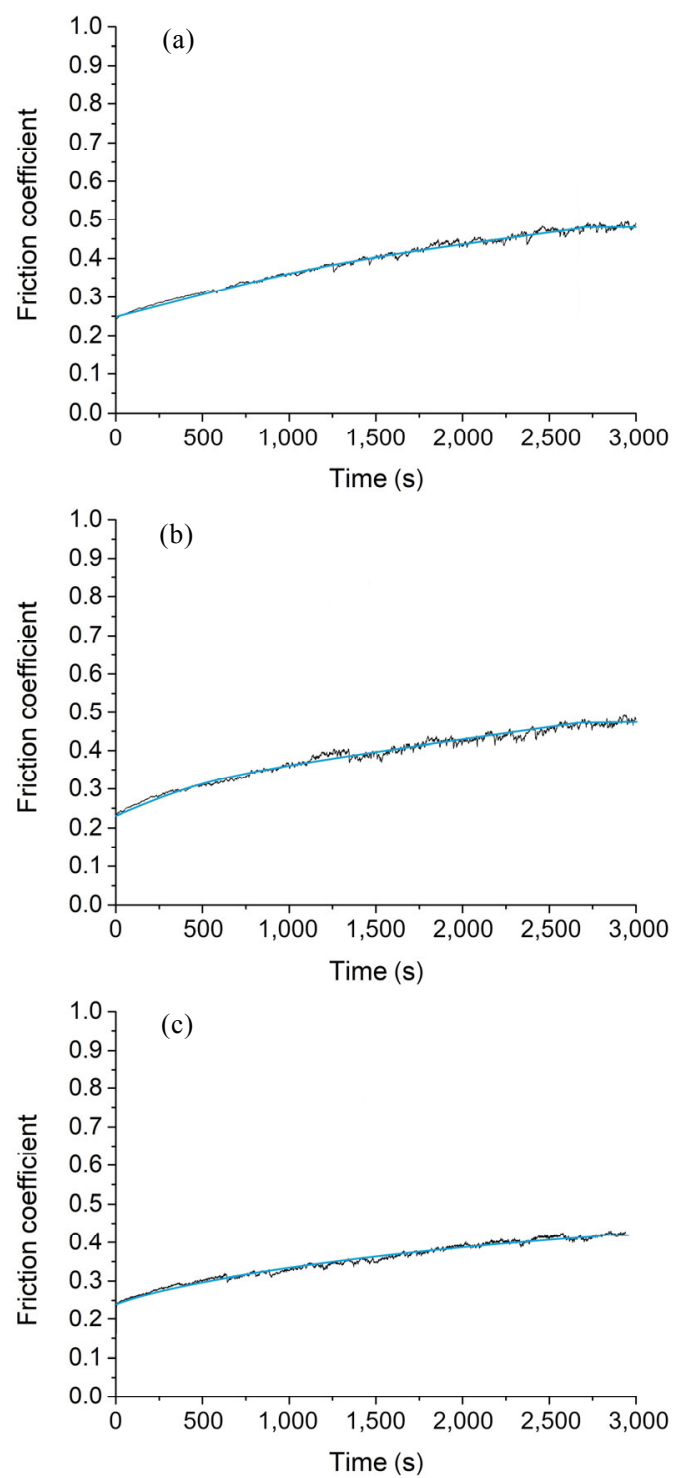

Fig. 6 Experimental curves of friction coefficient recorded during RT tests of (a) FM1, (b) FM2, and (c) FM3 pins tested against WC-FeCrAlY-coated disc.
Table 3 Steady-state friction coefficients and specific wear coefficient of the three different friction material PoD tested at RT against WC-FeCrAlY-coated discs.

\begin{tabular}{cccc}
\hline $\begin{array}{c}\text { Friction } \\
\text { material- } \\
\text { pin }\end{array}$ & $\begin{array}{c}\text { Friction } \\
\text { coefficient at } \\
\text { end of the tests }\end{array}$ & $\begin{array}{c}\text { Specific wear } \\
\text { coefficient of } \\
\text { the pin }\left(\mathrm{m}^{2} / \mathrm{N}\right)\end{array}$ & $\begin{array}{c}\text { Specific wear } \\
\text { coefficient of the } \\
\text { disc }\left(\mathrm{m}^{2} / \mathrm{N}\right)\end{array}$ \\
\hline FM1 & 0.48 & $(1.2 \pm 0.7) \times 10^{-14}$ & $(1.4 \pm 0.1) \times 10^{-14}$ \\
FM2 & 0.47 & $(1.2 \pm 0.5) \times 10^{-14}$ & $(1.55 \pm 0.01) \times 10^{-14}$ \\
FM3 & 0.39 & $(5.9 \pm 0.2) \times 10^{-15}$ & - \\
\hline
\end{tabular}
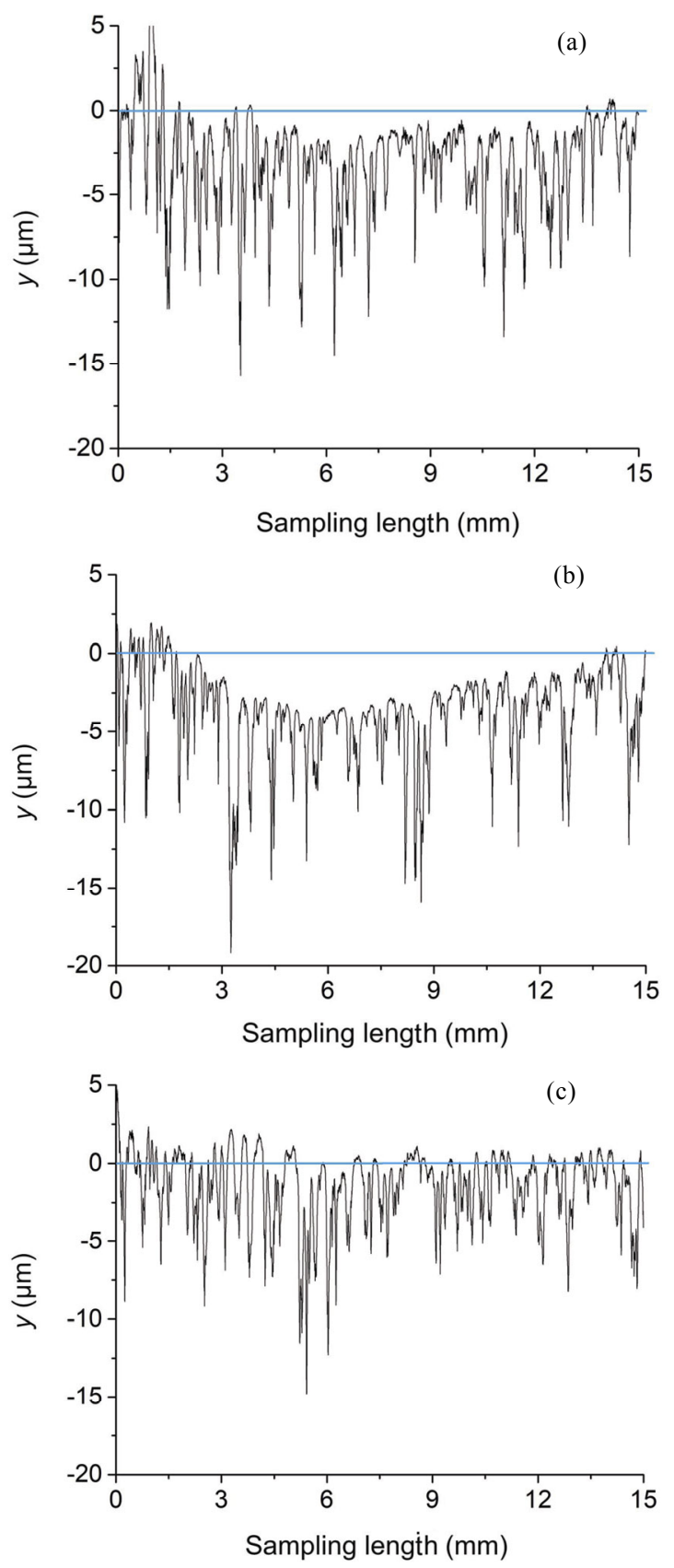

Fig. 7 Wear track profiles on WC-FeCrAlY-coated discs tested at RT of (a) FM1, (b) FM 2, and (c) FM3. 
the experimental setup. Furthermore, the specific wear rates were less than $2 \times 10^{-14} \mathrm{~m}^{2} / \mathrm{N}$; therefore, they can be regarded as mild in all cases [42]. It is noteworthy that when evaluating the wear volumes from the profiles, we did not consider the surface porosity of the worn surfaces.

The SEM observations of the top and cross-sections of the worn pins tested at RT are shown in Fig. 8. The friction layers on the pin-worn surfaces comprised of primary and secondary plateaus. For these types of materials, the primary plateaus comprised hard particles or fibers, against which the worn debris accumulated and compacted to form secondary plateaus [43-45]. To highlight the extension of the secondary plateaus, they are shown as colored regions in Figs. 8(d)-8(f). The fraction of the pin area covered by the secondary plateaus can be estimated from these images. FM1 showed a $27 \%$ coverage; FM2, $12 \%$; and FM3, 58\%. Furthermore, in the case of FM2 (Fig. 8(b)), the friction layer was discovered only above the metallic constituents of the formulation, whereas FM3 showed widespread and well-compacted secondary plateaus. The degree of compaction of the plateaus can be evaluated more effectively from the cross-sectional views shown in Figs. 8(g)-8(i), where the sliding directions are shown by arrows. The first two friction materials showed scarcely compacted secondary plateaus, featuring relatively coarse wear debris. In FM3, the secondary plateaus were particularly well compacted. As observed from the labels in Figs. 8(d)-8(f), secondary plateaus formed on the reinforcing metal fibers in the FM1 and FM3 cases, whereas they were mainly formed against an $\mathrm{Al}_{2} \mathrm{O}_{3}$ particle in the $\mathrm{FM} 2$ case.
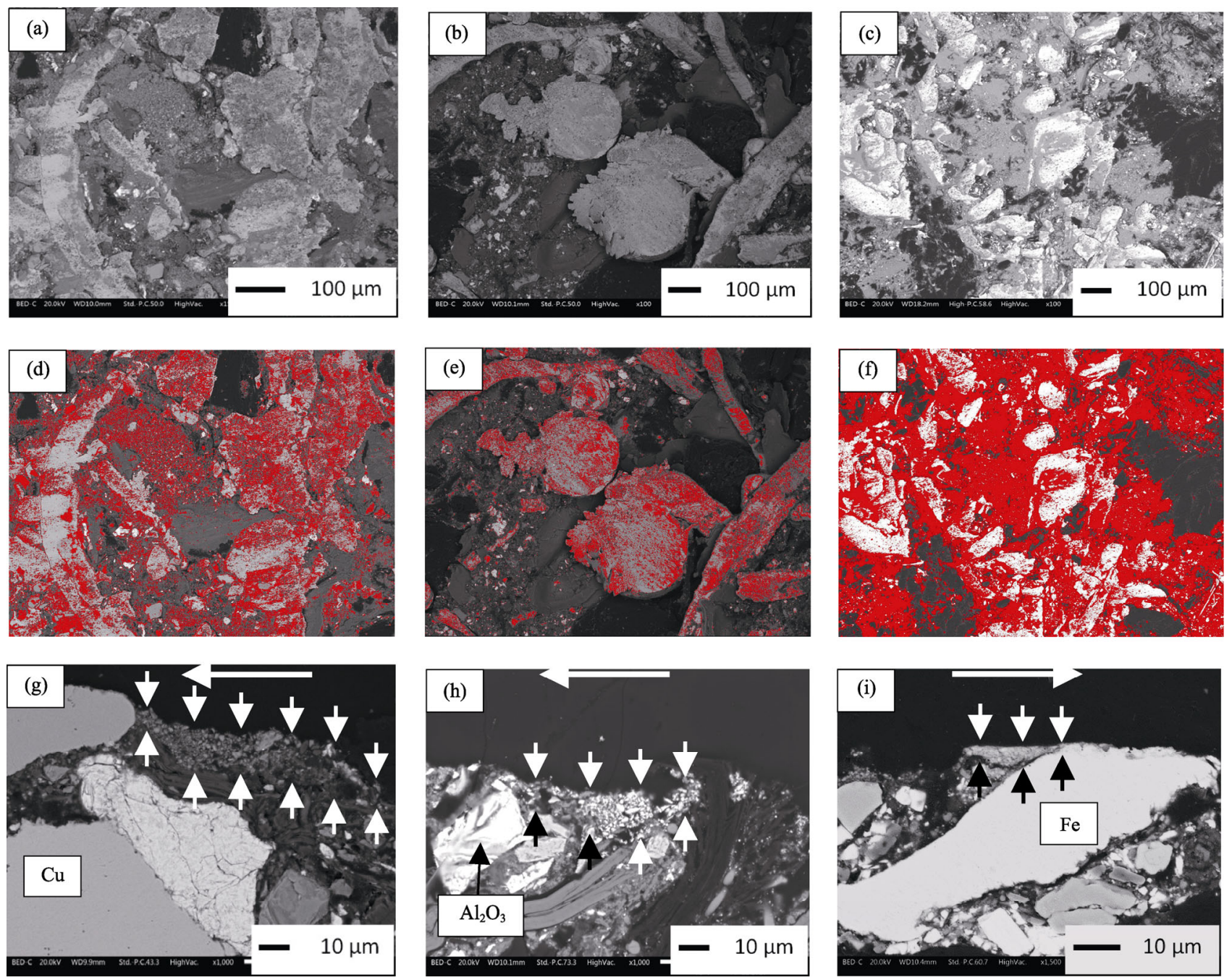

Fig. 8 (a-c) Top view; (d-f) top view with colored secondary plateaus; ( $\mathrm{g}-\mathrm{i})$ cross-sectional SEM observation of worn surfaces of FM1, FM2, and FM3 pins, respectively. Arrows indicate secondary plateaus. 
The EDXS analyses were performed on the crosssections of the secondary plateaus, as shown in Fig. 8 . The results of the relevant analyses are shown in Table 4. It is noteworthy that the reported concentration values are useful only for relative comparison, as their absolute values may deviate significantly from the actual values. In fact, each measurement was affected by instrumental inaccuracies and, most importantly, by the uncertainty correlated with the sampling volume. It was observed that the secondary plateaus contained almost all the elements originally present in the friction materials. In addition, they contained $\mathrm{W}$, which was transferred from the coating counterface. The Fe content was high, suggesting that part of it was from the coating.

The SEM micrograph of the worn surface of the coated disc tested against FM1 is shown in Fig. 9. The surfaces of the discs tested against the other

Table 4 Results of EDXS analysis performed on the crosssection of secondary plateaus of pins tested at RT.

\begin{tabular}{cccc}
\hline $\begin{array}{c}\text { Detected element } \\
(\mathrm{wt} \%)\end{array}$ & FM1 & FM2 & FM3 \\
\hline $\mathrm{Cu}$ & $16 \pm 2$ & $10 \pm 1$ & - \\
$\mathrm{Sn}$ & $7 \pm 1$ & $6.5 \pm 0.7$ & $4.2 \pm 0.9$ \\
$\mathrm{Fe}$ & $24 \pm 2$ & $24 \pm 2$ & $52.0 \pm 0.7$ \\
$\mathrm{O}$ & $13.6 \pm 0.6$ & $13 \pm 3$ & $12.9 \pm 0.8$ \\
$\mathrm{~W}$ & $14 \pm 4$ & $19 \pm 2$ & $9.9 \pm 0.6$ \\
$\mathrm{Cr}$ & $5 \pm 2$ & $3.9 \pm 0.5$ & $1.6 \pm 0.2$ \\
$\mathrm{Zn}$ & $9 \pm 4$ & $8.1 \pm 0.7$ & - \\
$\mathrm{Mg}$ & $5 \pm 2$ & $2.4 \pm 0.1$ & $6.1 \pm 0.3$ \\
$\mathrm{Si}$ & $2 \pm 1$ & $2.3 \pm 0.2$ & $1.0 \pm 0.1$ \\
$\mathrm{Al}$ & $4.4 \pm 0.8$ & $5.9 \pm 0.2$ & $3.7 \pm 0.5$ \\
$\mathrm{Ti}$ & - & $4.9 \pm 0.5$ & - \\
$\mathrm{Ba}$ & - & - & $8.6 \pm 0.5$ \\
\hline
\end{tabular}

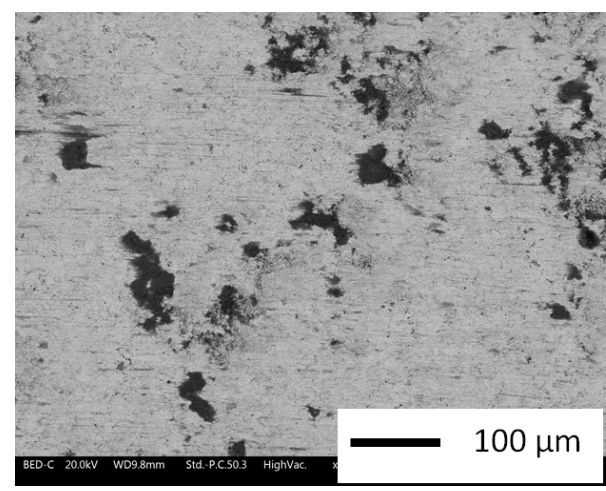

Fig. 9 SEM micrographs of worn surfaces of coated discs in RT tests for FM1. friction materials showed the same features as in Fig. 9. Hence, they are not presented herein. The worn surface of the coated disc was characterized by the accumulation and compaction of the pin wear debris inside the unpolished valleys of the coatings (darker regions in Fig. 9).

\subsection{HT sliding tests}

Figure 10 shows the experimental curves depicting the evolution of the friction coefficient for the three materials. As shown, they differed completely from the curves recorded at RT. For materials FM1 and FM2, the steady-state started from the beginning, as observed in conventional $\mathrm{WC}-\mathrm{CoCr}$ and $\mathrm{Cr}_{3} \mathrm{C}_{2}-\mathrm{NiCr}$ coatings at HT [12]. The friction coefficient values
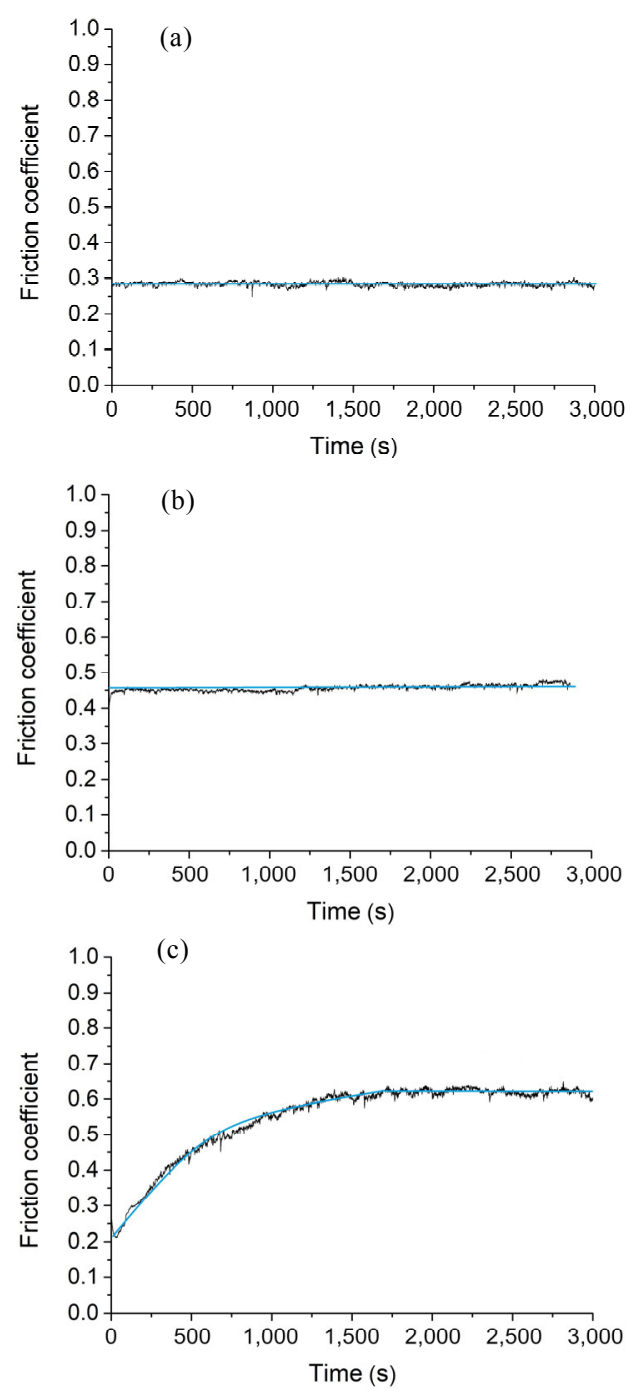

Fig. 10 Experimental curves of friction coefficient acquired during HT tests of (a) FM1, (b) FM2, and (c) FM3. 
(summarized in Table 5) were lower than those recorded at RT. For FM3, an initial stage with a continuous increase in the friction coefficient was observed (similar to the RT tests), and steady- state conditions were attained after 1,750 s of sliding. In this case, the steady-state value of the friction coefficient was much higher than that recorded at RT.

The disc wear track profiles are shown in Fig. 11. In Table 5, the calculated wear coefficients for the pin and discs are listed. The wear behaviors of the pins are comparable for the first two formulations,

whereas the specific wear coefficient of FM3 was slightly lower than that of the other two formulations. As expected, by comparing the pin wear data in Table 3 with those in Table 5, it can be inferred that the HT resulted in higher specific wear coefficients, with a general increase of approximately six times for the first two formulations, and by one order of magnitude for FM3. The wear of the coated discs tested at HT was not detected in FM1 and FM3, whereas it decreased in FM2 when tested at RT (Table 3).

The SEM images of the worn surfaces of the pins tested at HT are shown in Fig. 12. A general increase in the area of the secondary plateaus with respect to the RT case (Fig. 8) is shown. From the estimation of the covered area, FM1 showed coverage of $33 \%$; FM2, 53\%; and FM3, 64\%. The most compacted and widespread secondary plateaus were those observed on the FM3 pins (Fig. 12(c)). Moreover, FM1 exhibited poorly compacted plateaus, as shown from the top view (Fig. 12(a)). From the cross-sectional views, the plateaus of FM2 were those in which the largest wear fragments were observed. However, FM3 showed well compacted and thin secondary plateaus.

In Table 6, the EDXS results of the analysis conducted on the cross-sections of the secondary plateaus shown in the micrographs in Fig. 12 are listed. The dataset suggests a decrease with respect to the RT results in the material transfer, from the coated disc surfaces toward the pin plateaus. The amounts of tungsten inside the secondary plateaus were comparable for FM1 and FM3 but lower for FM2. Moreover, the tungsten content was lower than that in the RT tests.

The SEM images of the worn surfaces of the coated discs tested at HT are shown in Fig. 13. As shown, the material transfer from the pin increased in the RT tests (compare Fig. 13 with Fig. 9).

Table 5 Steady-state friction coefficient and specific wear coefficients of the three friction materials, for the tests performed at HT $\left(300{ }^{\circ} \mathrm{C}\right)$.

\begin{tabular}{cccc}
\hline Material & $\begin{array}{c}\text { Steady-state } \\
\text { friction } \\
\text { coefficient }\end{array}$ & $\begin{array}{c}\text { Specific wear } \\
\text { coefficient of the } \\
\text { pin }\left(\mathrm{m}^{2} / \mathrm{N}\right)\end{array}$ & $\begin{array}{c}\text { Specific wear } \\
\text { coefficient of the } \\
\text { disc }\left(\mathrm{m}^{2} / \mathrm{N}\right)\end{array}$ \\
\hline FM1 & 0.28 & $(6.7 \pm 0.7) \times 10^{-14}$ & - \\
FM2 & 0.45 & $(7.0 \pm 0.6) \times 10^{-14}$ & $(8.7 \pm 0.5) \times 10^{-15}$ \\
FM3 & 0.62 & $(5.5 \pm 0.8) \times 10^{-14}$ & - \\
\hline
\end{tabular}
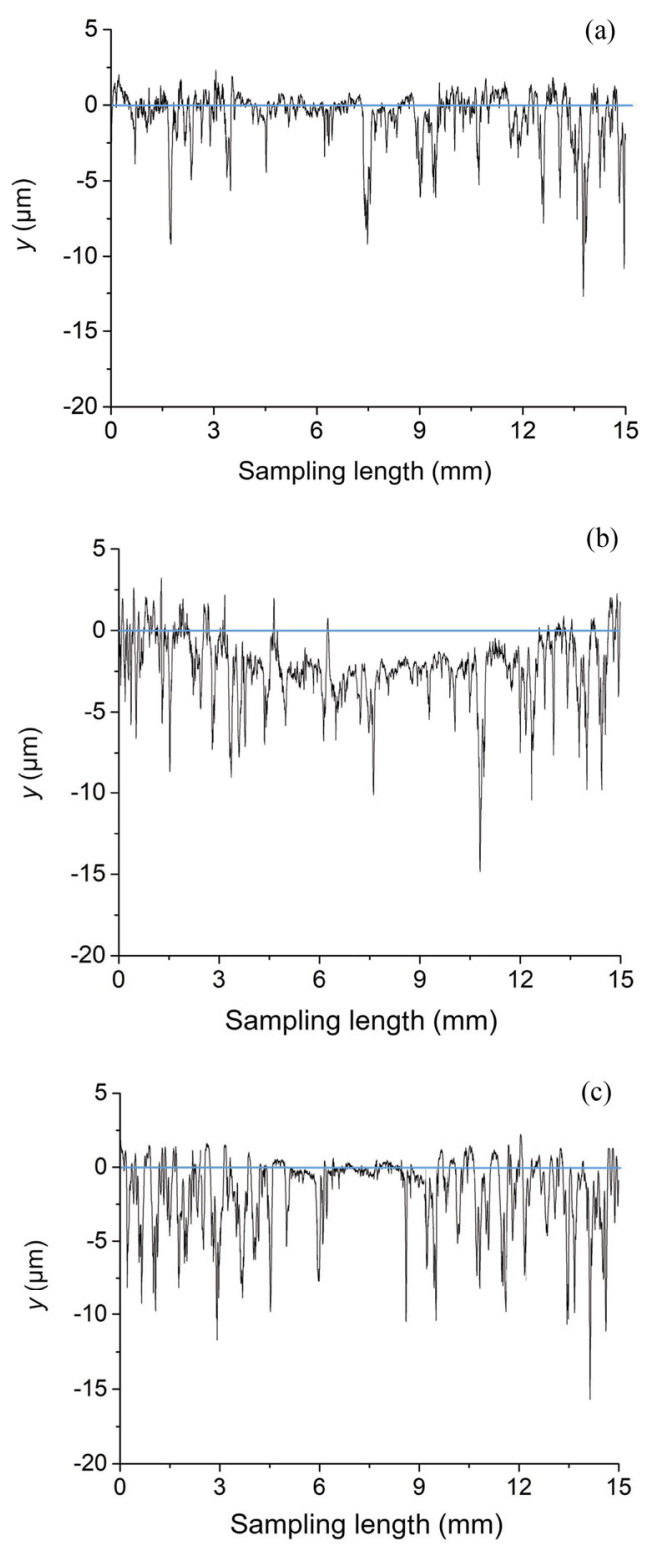

Fig. 11 Wear track profiles on WC-FeCrAlY-coated discs tested at HT with (a) FM1, (b) FM 2, and (c) FM 3. 

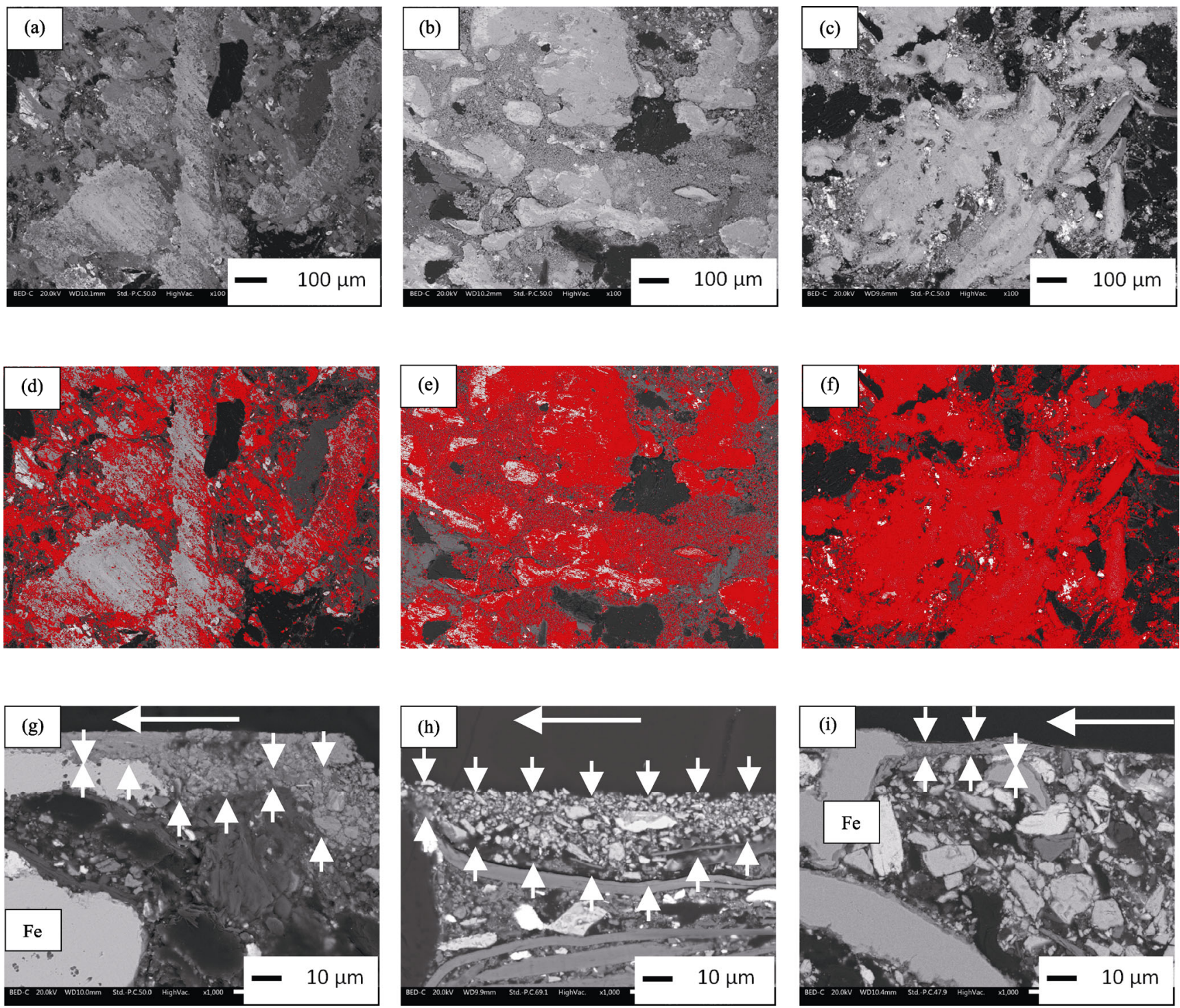

Fig. 12 (a-c) Top view; $(\mathrm{d}-\mathrm{f})$ top view with highlighted secondary plateaus; $(\mathrm{g}-\mathrm{i})$ cross-sectional SEM observation of worn surfaces of FM 1, FM 2, and FM3 in HT tests, respectively.
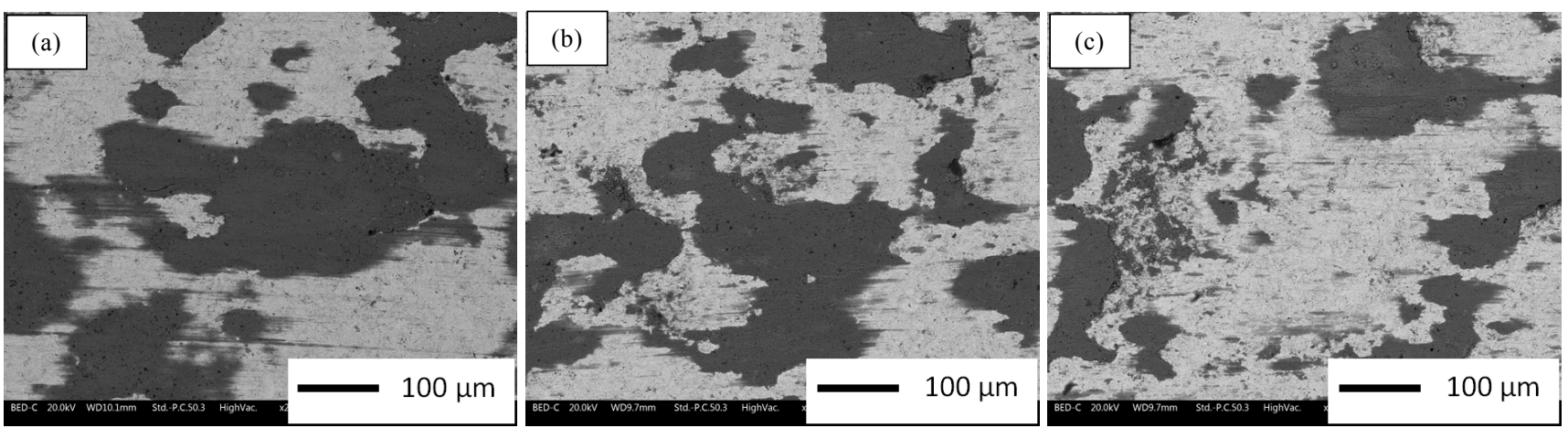

Fig. 13 SEM micrographs of worn surfaces of coated discs in HT tests for (a) FM1, (b) FM2, and (c) FM3. 
Table 6 Results of EDXS analysis performed on the crosssection of secondary plateaus of pins tested at HT.

\begin{tabular}{cccc}
\hline $\begin{array}{c}\text { Detected element } \\
(\mathrm{wt} \%)\end{array}$ & FM1 & FM2 & FM3 \\
\hline $\mathrm{Cu}$ & $24 \pm 2$ & $13.4 \pm 0.5$ & - \\
$\mathrm{Sn}$ & $7.1 \pm 0.6$ & $7 \pm 2$ & $6.7 \pm 0.5$ \\
$\mathrm{Fe}$ & $26 \pm 2$ & $36 \pm 2$ & $48.7 \pm 0.9$ \\
$\mathrm{O}$ & $14 \pm 4$ & $12 \pm 2$ & $21.0 \pm 2$ \\
$\mathrm{~W}$ & $4.1 \pm 0.4$ & $1.8 \pm 0.3$ & $4.2 \pm 0.2$ \\
$\mathrm{Cr}$ & $2.6 \pm 0.2$ & $3.2 \pm 0.2$ & $1.7 \pm 0.2$ \\
$\mathrm{Zn}$ & $12.1 \pm 0.9$ & $6.7 \pm 0.1$ & - \\
$\mathrm{Mg}$ & $3.8 \pm 0.6$ & $3.4 \pm 0.1$ & $5.3 \pm 0.6$ \\
$\mathrm{Si}$ & $1.8 \pm 0.3$ & $3.6 \pm 0.1$ & $0.3 \pm 0.1$ \\
$\mathrm{Al}$ & $4.5 \pm 0.4$ & $8 \pm 2$ & $3.7 \pm 0.5$ \\
$\mathrm{Ti}$ & - & $4.9 \pm 0.2$ & - \\
$\mathrm{Ba}$ & - & - & $8.4 \pm 0.6$ \\
\hline
\end{tabular}

\section{Discussion}

Owing to the high wear resistance of the cermet coatings, the contact plateaus were mainly formed by the compaction of wear debris from the pin only. Hence, as observed in a previous investigation focusing on traditional $\mathrm{WC}-\mathrm{CoCr}$ and $\mathrm{Cr}_{3} \mathrm{C}_{2}-\mathrm{NiCr}$ coatings [17], the running-in stages were much longer compared with the case involving sliding against cast-iron discs $[12,44]$.

The friction coefficients at the end of the RT tests were 0.48 and 0.47 for FM1 and FM2, respectively. These values were lower than 0.66 recorded for the case involving sliding against the conventional WC$\mathrm{CoCr}$ coating vs. FM1 under the same conditions [12]. This result can be explained by the relatively high $\mathrm{Cu}$ content in the friction material and hence in the friction layer, as well as the high tribological compatibility between $\mathrm{Cu}$ and $\mathrm{Co}$, as highlighted by Furushima et al. [46], who investigated the dry sliding behavior of WC-Co coating against copper. The high adhesive interaction at the mating asperities explains the high friction coefficient observed in the cited study [12]. Moreover, the abrasives in FM1 and FM2 did not significantly increase the friction coefficient, as they did when sliding against a cast-iron counterface. In fact, in the latter case, the abrasives removed metallic debris from the counterface to form ironoxide particles accumulating in the contact plateaus, thereby increasing the friction coefficient value [45, $47,48]$. However, when they were sliding against a hard cermet coating, this contribution was lost. The low friction coefficient of FM3 (0.39, see Table 3) can be explained by considering the composition of the friction layer. It is rich in barite particles (Table 4), which are extremely small (Fig. 5) and form highly compacted and smooth friction layers, as revealed in previous investigations [41, 49]. Therefore, the friction coefficient was low because of the low adhesion forces that developed between the barite-rich friction layer and the cermet counterface, owing to the high chemical inertness of barite [50].

The experimental curves of the friction coefficient acquired during the HT tests revealed that the temperature significantly enhanced the kinetics of formation of the secondary plateaus on the pins and of the related layer transferred onto the coated disc surfaces. This was revealed in the running-in stages, which were absent in FM1 and FM2 and extremely short in FM3 (Fig. 10). This behavior can be attributed to the partial thermal degradation of the friction materials, particularly of the phenolic resin that served as a binder $[12,29,51,52]$. The thermal degradation phenomena were responsible for the increase in the specific wear coefficients of the pins in the RT tests. This increase in the wear of the pins was related to a higher amount of wear debris at the mating interface, resulting in an easier formation of the secondary plateaus and a shorter or missing running-in stage. Additionally, the thermal degradation at the sliding interface contributed to the decrease in the friction coefficients of FM1 and FM2. The most significant decrease (from 0.48 to 0.28 ) was detected in FM1, although a slight reduction was recorded in FM2 as well, i.e., from 0.48 to 0.45 . Furthermore, FM2 was the only material that resulted in a worn WC-FeCrAlY disc counterface in the HT tests. In fact, the increased amount of $\mathrm{TiO}_{2}$ significantly abraded the coating, thereby worsening its wear resistance performance.

A peculiar behavior featuring a comparatively higher friction coefficient was exhibited by FM3. This can be explained by considering the high amount of steel fibers in this material (Fig. 5 and Table 2). The increasing trend of the experimental curve of 
the friction coefficient might be related to the oxidative phenomena at the interface between the steel fibers and WC-FeCrAlY-coated disc. It can be assumed that this oxidation may favor high adhesional forces and result in a friction coefficient that is approximately that of iron oxide-iron oxide dry sliding contact [53-57]. The disc surface was primarily covered by iron oxides and the fraction of iron oxides in the secondary plateaus increased, thereby increasing the adhesion to the friction coefficient. In fact, Zhang et al. [58] identified a temperature between 250 and $400{ }^{\circ} \mathrm{C}$ as critical for promoting steel oxidation as well as determining its frictional and wear behavior under sliding conditions. This explanation was supported by the EDXS analyses of Fe and $\mathrm{O}$ in the secondary plateaus. At RT (Table 4), the Fe content in FM3 was high (52\%), whereas the O content was only $12.9 \%$. This value was similar to the oxygen concentration values measured in FM1 and FM2. At $300{ }^{\circ} \mathrm{C}$, the Fe content was still high (48.7\%), but the $\mathrm{O}$ content increased to $21 \%$. It can be concluded that the increased temperature favored the oxidation of Fe. To verify this explanation, we performed an RT sliding test on the tribological system tested at $300{ }^{\circ} \mathrm{C}$. A comparison of the friction coefficients of the three materials are shown in Fig. 14. As shown, the friction layer that formed at $300{ }^{\circ} \mathrm{C}$, which was present from the beginning of the repeated tests, guaranteed a higher friction coefficient even during subsequent RT tests.

At RT, the wear of the pins was mild, particularly

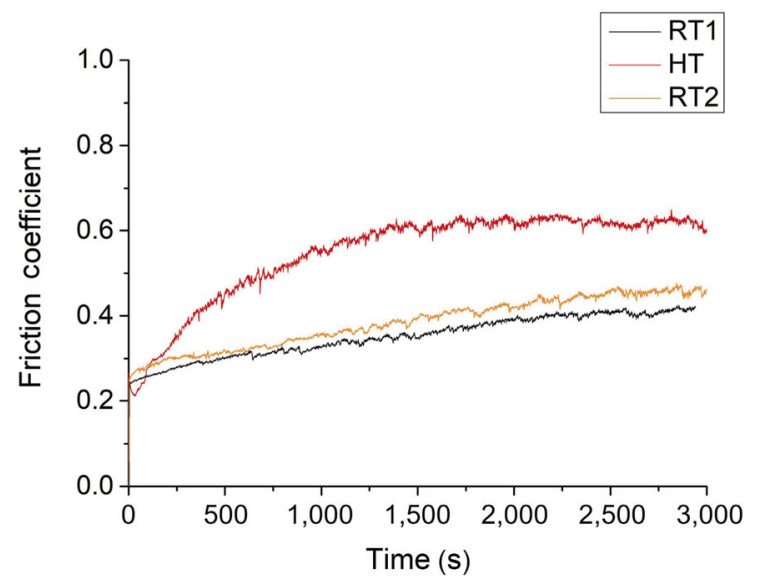

Fig. 14 Comparison of experimental friction coefficient curves of FM3 acquired at RT (RT1), $300{ }^{\circ} \mathrm{C}$ (HT), and RT after the test at $300{ }^{\circ} \mathrm{C}$ (RT2). for FM3. In addition, when using the FM3 pin, no wear was detected on the coating. From the chemical analysis of the pin secondary plateaus, it was observed that the Fe content increased with respect to the original composition of the friction materials (compare Tables 1 with 4). Fe originated from the steel fibers of the friction materials and the transfer from the matrix of the WC-FeCrAlY coating. This latter observation agreed well with the high and comparable presence of tungsten in the secondary plateaus of FM1 and FM2, as well as with the wear detected on the coated disc (Table 3). By contrast, the presence of lower amounts of $\mathrm{W}$ and Fe in the secondary plateaus of FM3 confirmed that this material was less aggressive against the WC-FeCrAlY-coated disc counterface and that it did not wear out the coated disc surface during sliding.

At $300{ }^{\circ} \mathrm{C}$, the pin wear increased at RT and became severe. This result was reflected by the increase in the secondary plateau coverage at RT (Figs. 12(a)12(c)). Coherently, with the RT observations and the friction coefficients detected during the HT tests, the best compacted, thin, and widespread plateaus were shown by FM3 (compare the images of Figs. 12(d)-12(f)). This behavior can be associated with the synergistic effect of steel fiber and barite. Less compacted secondary plateaus were exhibited by FM2, owing to the presence of $\mathrm{TiO}_{2}$. Its high content inside the formulation, together with its high hardness, hindered the appropriate compaction of the wear debris, particularly during the HT tests. As shown in Table 5, the specific wear coefficients of the discs were not reported for the tests performed with FM1 and FM3. This was because of the high transfer of material from the pin to the disc surface in the case of FM1, and the material transfer and low aggressivity on the counterface in the case of the FM3. As shown in Table 3, the FM3 formulation was the only one that did not wear out the disc during the RT tests.

The tungsten transferred from the coating counterface (Table 6) in the RT tests reduced because, during the HT testing, the majority of the wear fragments were produced by the pin, resulting in a lower relative content of elements transferred from the coating. In fact, no disc wear was detected after it slid against 
FM1 and FM3. Moreover, a less significant disc wear than that at RT was reported for FM2. These results agreed well with the higher fraction of friction material transfer occurring at HT on the disc surface (Fig. 13).

\section{Conclusions}

The frictional and wear behavior of WC-FeCrAlYcoated discs against three commercial friction materials were investigated via PoD dry sliding tests. The tests were performed at RT and $300{ }^{\circ} \mathrm{C}$. The main results can be summarized as follows:

1) At RT, the evolution of the friction coefficients demonstrated a long running-in period with a continuous increase in the friction coefficient, depending on the mild wear regime under these testing conditions.

2) FM3 showed the lowest friction coefficient value (0.39), mainly because of the high content of barite filler particles observed in the well-compacted friction layer. Additionally, it featured a lower content of abrasives compared with FM1 and FM2.

3) At $300{ }^{\circ} \mathrm{C}$, no running-in was observed for FM1 and FM2, whereas a running-in period was observed for FM3, reaching a comparatively high coefficient of friction (0.62). This behavior, typical of severe wear, was attributed to the high content of steel fibers in FM3 and the corresponding formation of oxidized fragments. FM3 demonstrated an acceptable average friction coefficient when tested at RT after the test at $300{ }^{\circ} \mathrm{C}$.

4) FM3 showed the lowest wear rate at RT and HT.

5) The FM3-Co-free cermet coating coupling exhibited the best combination of tribological and durability performances.

\section{Acknowledgements}

This study was funded by the European Union's Horizon 2020 Research and Innovation Programme under grant agreement (No. 636592 (LOWBRASYS project)). The authors thank Flame Spray, Roncello, $\mathrm{MB}$, Italy, for the coatings.

Open Access This article is licensed under a Creative Commons Attribution 4.0 International License, which permits use, sharing, adaptation, distribution and reproduction in any medium or format, as long as you give appropriate credit to the original author(s) and the source, provide a link to the Creative Commons licence, and indicate if changes were made.

The images or other third party material in this article are included in the article's Creative Commons licence, unless indicated otherwise in a credit line to the material. If material is not included in the article's Creative Commons licence and your intended use is not permitted by statutory regulation or exceeds the permitted use, you will need to obtain permission directly from the copyright holder.

To view a copy of this licence, visit http://creativecommons.org/licenses/by/4.0/.

\section{References}

[1] Davis J R. Handbook of Thermal Spray Technology. Materials Park (USA): ASM International, 2004.

[2] Pawlowski L. The Science and Engineering of Thermal Spray Coatings. 2nd edn. Chichester (UK): John Wiley \& Sons, Ltd, 2008.

[3] Kreye H, Schwetzke R, Zimmerman S, Berndt C C, eds. Thermal Spray: Practical Solutions for Engineering Problems. Materials PArk, Ohio (USA): ASM INternational, 1996.

[4] Sahraoui T, Fenineche N E, Montavon G, Coddet C. Structure and wear behaviour of HVOF sprayed $\mathrm{Cr}_{3} \mathrm{C}_{2}-\mathrm{NiCr}$ and WC-Co coatings. Mater Des 24(5): 309-313 (2003)

[5] Sidhu H S, Sidhu B S, Prakash S. Wear characteristics of $\mathrm{Cr}_{3} \mathrm{C}_{2}-\mathrm{NiCr}$ and WC-Co coatings deposited by LPG fueled HVOF. Tribol Int 43(5-6): 887-890 (2010)

[6] Valarezo A, Bolelli G, Choi W B, Sampath S, Cannillo V, Lusvarghi L, Rosa R. Damage tolerant functionally graded WC-Co/Stainless Steel HVOF coatings. Surf Coat Technol 205(7): 2197-2208 (2010)

[7] LaVecchia M G, Mor F, Straffelini G, Doni D. Microstructure and sliding wear behavior of thermal spray carbide coatings. Int J Powder Metall 35(2): 37-46 (1999)

[8] Zhang W C, Liu L B, Zhang M T, Huang G X, Liang J S, Li X, Zhang L G. Comparison between WC-10Co-4Cr and $\mathrm{Cr}_{3} \mathrm{C}_{2}-25 \mathrm{NiCr}$ coatings sprayed on $\mathrm{H} 13$ steel by HVOF. Trans Nonferr Met Soc China 25(11): 3700-3707 (2015)

[9] Bolelli G, Berger L M, Bonetti M, Lusvarghi L. Comparative study of the dry sliding wear behaviour of 
HVOF-sprayed WC- $-(\mathrm{W}, \mathrm{Cr})_{2} \mathrm{C}-\mathrm{Ni}$ and $\mathrm{WC}-\mathrm{CoCr}$ hardmetal coatings. Wear 309(1-2): 96-111 (2014)

[10] Bolelli G, Berger L M, Börner T, Koivuluoto $H$, Lusvarghi L, Lyphout C, Markocsan N, Matikainen V, Nylén P, Sassatelli P, et al. Tribology of HVOF- and HVAF-sprayed WC-10Co4Cr hardmetal coatings: A comparative assessment. Surf Coat Technol 265: 125-144 (2015)

[11] Bolelli G, Berger L M, Börner T, Koivuluoto $H$, Matikainen V, Lusvarghi L, Lyphout C, Markocsan N, Nylén $\mathrm{P}$, Sassatelli $\mathrm{P}$, et al. Sliding and abrasive wear behaviour of HVOF- and HVAF-sprayed $\mathrm{Cr}_{3} \mathrm{C}_{2}-\mathrm{NiCr}$ hardmetal coatings. Wear 358-359: 32-50 (2016)

[12] Federici M, Menapace C, Moscatelli A, Gialanella S, Straffelini G. Pin-on-disc study of a friction material dry sliding against HVOF coated discs at room temperature and $300^{\circ} \mathrm{C}$. Tribol Int 115: 89-99 (2017)

[13] Watremez M, Bricout J P, Marguet B, Oudin J. Friction, temperature, and wear analysis for ceramic coated brake disks. J Tribol 118(3): 457-465 (1996)

[14] Öz A, Gürbüz H, Yakut A K, Sağiroğlu S. Braking performance and noise in excessive worn brake discs coated with HVOF thermal spray process. J Mech Sci Technol 31(2): 535-543 (2017)

[15] Wahlström J, Söderberg A, Olander L, Jansson A, Olofsson U. A pin-on-disc simulation of airborne wear particles from disc brakes. Wear 268(5-6): 763-769 (2010)

[16] Federici M, Menapace C, Moscatelli A, Gialanella S, Straffelini G. Effect of roughness on the wear behavior of HVOF coatings dry sliding against a friction material. Wear 368-369: 326-334 (2016)

[17] Federici M, Perricone G, Gialanella S, Straffelini G. Sliding behaviour of friction material against cermet coatings: Pin-on-disc study of the running-in stage. Tribol Lett 66(2): 53 (2018)

[18] Wahlström J, Lyu Y Z, Matjeka V, Söderberg A. A pin-on-disc tribometer study of disc brake contact pairs with respect to wear and airborne particle emissions. Wear 384-385: 124-130 (2017)

[19] Menapace C, Mancini A, Federici M, Straffelini G, Gialanella S. Characterization of airborne wear debris produced by brake pads pressed against HVOF-coated discs. Friction 8(2): 421-432 (2020)

[20] Information on https://echa.europa.eu/candidate-list-table.

[21] Zhang C, Liu L, Chan K C, Chen Q, Tang C Y. Wear behavior of HVOF-sprayed Fe-based amorphous coatings. Intermetallics 29: 80-85 (2012)

[22] Milanti A, Koivuluoto H, Vuoristo P, Bolelli G, Bozza F, Lusvarghi L. Microstructural characteristics and tribological behavior of HVOF-sprayed novel Fe-based alloy coatings. Coatings 4(1): 98-120 (2014)
[23] Terajima T, Takeuchi F, Nakata K, Adachi S, Nakashima $\mathrm{K}$, Igarashi $\mathrm{T}$. Composite coating containing $\mathrm{WC} / 12 \mathrm{Co}$ cermet and Fe-based metallic glass deposited by high-velocity oxygen fuel spraying. J Alloys Compd 504: S288-S291 (2010)

[24] Bolelli G, Börner T, Bozza F, Cannillo V, Cirillo G, Lusvarghi L. Cermet coatings with Fe-based matrix as alternative to $\mathrm{WC}-\mathrm{CoCr}$ : Mechanical and tribological behaviours. Surf Coat Technol 206(19-20): 4079-4094 (2012)

[25] Bolelli G, Bursi M, Lusvarghi L, Manfredini T, Matikainen V, Rigon R, Sassatelli P, Vuoristo P. Tribology of FeVCrC coatings deposited by HVOF and HVAF thermal spray processes. Wear 394-395: 113-133 (2018)

[26] Bolelli G, Colella A, Lusvarghi L, Puddu P, Rigon R, Sassatelli P, Testa V. Properties of HVOF-sprayed TiC-FeCrAl coatings. Wear 418-419: 36-51 (2019)

[27] Perricone G, Matějka V, Alemani M, Valota G, Bonfanti A, Ciotti A, Olofsson U, Söderberg A, Wahlström J, Nosko $\mathrm{O}$, et al. A concept for reducing $\mathrm{PM}_{10}$ emissions for car brakes by 50\%. Wear 396-397: 135-145 (2018)

[28] Abbasi S, Jansson A, Olander L, Olofsson U, Sellgren U. A pin-on-disc study of the rate of airborne wear particle emissions from railway braking materials. Wear 284-285: 18-29 (2012)

[29] Verma P C, Ciudin R, Bonfanti A, Aswath P, Straffelini G, Gialanella S. Role of the friction layer in the high-temperature pin-on-disc study of a brake material. Wear 346-347: 56-65 (2016)

[30] Wang Y Y, Li C J, Ohmori A. Influence of substrate roughness on the bonding mechanisms of high velocity oxy-fuel sprayed coatings. Thin Solid Films 485(1-2): 141-147 (2005)

[31] Ksiazek M, Boron L, Tchorz A. Microstructure, mechanical properties and wear behavior of high-velocity oxygen-fuel (HVOF) sprayed $\left(\mathrm{Cr}_{3} \mathrm{C}_{2}-\mathrm{NiCr}+\mathrm{Al}\right)$ composite coating on ductile cast iron. Coatings 9(12): 840 (2019)

[32] Abbas M, Smith G M, Munroe P R. Microstructural characterization of HVOF-sprayed $\mathrm{Ni}$ on polished and oxidized stainless steel substrates. $J$ Therm Spray Technol 29(5): 1093-1110 (2020)

[33] Murthy J K N, Venkataraman B. Abrasive wear behaviour of $\mathrm{WC}-\mathrm{CoCr}$ and $\mathrm{Cr}_{3} \mathrm{C}_{2}-20(\mathrm{NiCr})$ deposited by HVOF and detonation spray processes. Surf Coat Technol 200(8): 2642-2652 (2006)

[34] Lekatou A, Sioulas D, Karantzalis A E, Grimanelis D. A comparative study on the microstructure and surface property evaluation of coatings produced from nanostructured and conventional WC-Co powders HVOF-sprayed on A17075. Surf Coat Technol 276: 539-556 (2015)

[35] Verdon C, Karimi A, Martin J L. A study of high 
velocity oxy-fuel thermally sprayed tungsten carbide based coatings. Part 1: Microstructures. Mater Sci Eng A 246(1-2): 11-24 (1998)

[36] Lutterotti L. Total pattern fitting for the combined size-strain-stress-texture determination in thin film diffraction. Nucl Instrum Methods Phys Res Sect B Beam Interact Mater Atoms 268(3-4): 334-340 (2010)

[37] Dante R C. Handbook of Friction Materials and Their Applications. Amsterdam (Netherlands): Elsevier, 2016.

[38] Straffelini G, Ciudin R, Ciotti A, Gialanella S. Present knowledge and perspectives on the role of copper in brake materials and related environmental issues: A critical assessment. Environ Pollut 207: 211-219 (2015)

[39] Sugözü B, Dağhan B. Effect of $\mathrm{BaSO}_{4}$ on tribological properties of brake friction materials. Int J Innov Res Sci, Eng Technol 5(12): 30-35 (2016)

[40] Menapace C, Leonardi M, Matějka V, Gialanella S, Straffelini G. Dry sliding behavior and friction layer formation in copper-free barite containing friction materials. Wear 398-399: 191-200 (2018)

[41] Federici M, Alemani M, Menapace C, Gialanella S, Perricone G, Straffelini G. A critical comparison of dynamometer data with pin-on-disc data for the same two friction material pairs-A case study. Wear 424-425: 40-47 (2019)

[42] Straffelini G. Friction and Wear: Methodologies for Design and Control. Cham (Germany): Springer, 2015.

[43] Verma P C, Menapace L, Bonfanti A, Ciudin R, Gialanella S, Straffelini G. Braking pad-disc system: Wear mechanisms and formation of wear fragments. Wear 322-323: 251-258 (2015)

[44] Straffelini G, Verma P C, Metinoz I, Ciudin R, Perricone $\mathrm{G}$, Gialanella S. Wear behavior of a low metallic friction material dry sliding against a cast iron disc: Role of the heat-treatment of the disc. Wear 348-349: 10-16 (2016)

[45] Straffelini G, Maines L. The relationship between wear of semimetallic friction materials and pearlitic cast iron in dry sliding. Wear 307(1-2): 75-80 (2013)

[46] Furushima R, Shimojima K, Hosokawa H, Matsumoto A. Oxidation-enhanced wear behavior of WC-FeAl cutting tools used in dry machining oxygen-free copper bars.

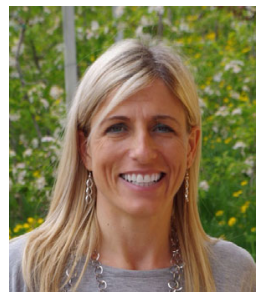

Cinzia MENAPACE. She graduated in materials engineering from the University of Trento in 1999. She received her Ph.D. degree in metallurgical engineering from the University of Padova, Italy, in
Wear 374-375: 104-112 (2017)

[47] Federici M, Gialanella S, Leonardi M, Perricone G, Straffelini G. A preliminary investigation on the use of the pin-on-disc test to simulate off-brake friction and wear characteristics of friction materials. Wear 410-411: 202-209 (2018)

[48] Jayashree P, Federici M, Bresciani L, Turani S, Sicigliano R, Straffelini G. Effect of steel counterface on the dry sliding behaviour of a $\mathrm{Cu}$-based metal matrix composite. Tribol Lett 66(4): 123 (2018)

[49] Aranganathan N, Bijwe J. Development of copper-free eco-friendly brake-friction material using novel ingredients. Wear 352-353: 79-91 (2016)

[50] Mahale V, Bijwe J, Sinha S. A step towards replacing copper in brake-pads by using stainless steel swarf. Wear 424-425: 133-142 (2019)

[51] Bode K, Ostermeyer G P. A comprehensive approach for the simulation of heat and heat-induced phenomena in friction materials. Wear 311(1-2): 47-56 (2014)

[52] Ramousse S, Høj J W, Sørensen O T. Thermal characterisation of brake pads. $J$ Therm Anal Calorim 64(3): 933-943 (2001)

[53] Lim S C, Ashby M F, Brunton J H. The effects of sliding conditions on the dry friction of metals. Acta Metall 37(3): 767-772 (1989)

[54] Gracia-Escosa E, García I, de Damborenea J J, Conde A. Friction and wear behaviour of tool steels sliding against 22MnB5 steel. J Mater Res Technol 6(3): 241-250 (2017)

[55] Lim S C, Ashby M F. Overview no. 55 Wear-mechanism maps. Acta Metall 35(1): 1-24 (1987)

[56] Banerji A, Lukitsch M J, McClory B, White D R, Alpas A T. Effect of iron oxides on sliding friction of thermally sprayed 1010 steel coated cylinder bores. Wear 376-377: 858-868 (2017)

[57] Hinrichs R, Vasconcellos M A Z, Österle W, Prietzel C. A TEM snapshot of magnetite formation in brakes: The role of the disc's cast iron graphite lamellae in third body formation. Wear 270(5-6): 365-370 (2011)

[58] Zhang Q Y, Chen K M, Wang L, Cui X H, Wang S Q. Characteristics of oxidative wear and oxidative mildwear. Tribol Int 61: 214-223 (2013)

2003. She has been working as a junior and senior researcher at the University of Trento for 20 years. Her current position is as a research assistant in metallurgy at the University of Trento, Italy. Her research interests include powder metallurgy, friction materials, and hot workability of metals. 


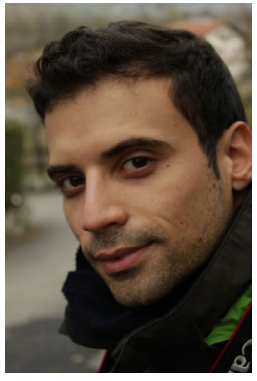

Alessandro MANCINI. He obtained his Ph.D. degree in chemistry at the University of Pavia in 2015, after completing his B.S. and M.S. degrees in the same university. Following the Ph.D. period, he

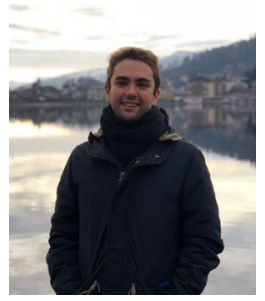

Matteo FEDERICI: He obtained his Ph.D. degree in materials, mechatronics, and systems Engineering at the University of Trento, Italy, in 2019. His Ph.D. project

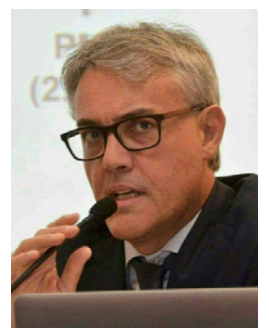

Giovanni STRAFFELINI. He received his M.S. degree in materials science and engineering from the University of Trento, Italy, in 1989, and his Ph.D. in metallurgical engineering from the University of Padova, in 1993. He is currently

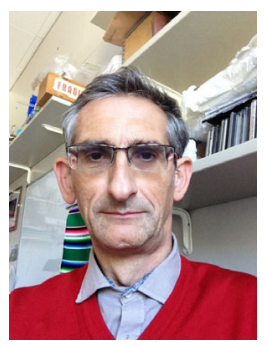

Stefano GIALANELLA. He is an associate professor in materials science and technology. His more recent research interests concern phase transformations, hightemperature oxidation and wear of structural alloys and materials joined Brembo as a research scientist in the Advance R\&D Department. His main activities focus on solid material characterization, in particular by means of X-ray techniques such as XRD, Fluorescence, and computed tomography.

aimed at developing and testing new materials for braking systems able to reduce the particulate matter emissions due to the wear of the brake components. Following a Ph.D. period, he joined Brembo as a research scientist.

a full professor in metallurgy at the University of Trento. His research interests include the mechanical properties of sintered alloys and weldments, the tribological behavior of materials, including friction materials for automotive and aerospace brakes, and the properties of surface engineered surfaces.

for brake systems, nanostructured materials and their microscopy characterization, archaeometry, and cultural heritage issues. On these and related subjects, he teaches courses for undergraduate and graduate students of the Departments of Industrial Engineering and Humanities in the University of Trento, Italy. 